
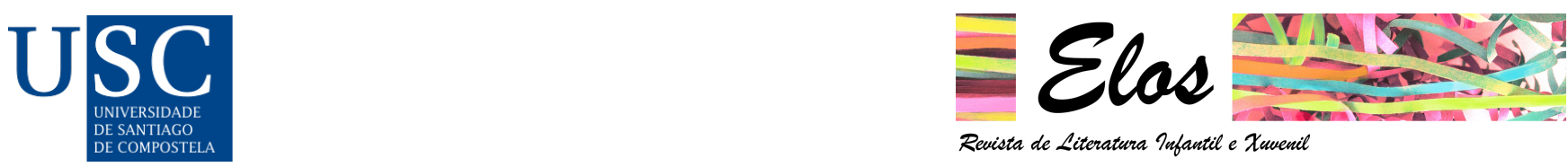

Elos: Revista de Literatura Infantil e Xuvenil, (8), 2021. ISSN: 2386-7620

https://doi.org/10.15304/elos.8.7097

Artigos

\title{
Narrar para fazer crer: a homoparentalidade em livros ilustrados infantis
}

\author{
Narrar para hacer creer: la homoparentalidad en álbumes \\ ilustrados infantiles \\ Narrate to believe: homoparenthood in children's picturebooks
}

\author{
Anabel Medeiros Azerêdo de Paula ${ }^{1}$ iD \\ ${ }^{1}$ Universidade Federal Fluminense, Brasil \\ anabel.azeredo@gmail.com
}

Recibido: 10/09/2020; Aceptado: 14/12/2020

\section{Resumo}

A Literatura Infantil contemporânea tem se mostrado um campo profícuo à abordagem de temas fraturantes (Ramos, 2009), que refletem as mudanças ocorridas na sociedade, ensejando obras consideradas controversas por trazerem à luz, dentre outras temáticas desafiadoras, a homoafetividade e a homoparentalidade. Pressupõe-se que narrativas constituídas por esses temas fraturantes em livros ilustrados de potencial destinação infantil podem assumir uma abordagem pragmática, intermediária entre o ético e o estético, narrando para convencer. Pretende-se, neste trabalho, analisar as narrativas verbovisuais: Amor de mãe (Carvalho, 2017) e Meus dois pais (Carrasco, 2010), a fim de investigar as estratégias discursivas utilizadas para o tratamento da homoafetividade e da homoparentalidade em um contrato comunicativo, cujo o destinatário potencial é a criança. 0 aporte teórico principal para analisar as narrativas selecionadas nesta pesquisa concentra-se na Teoria Semiolinguística de Análise do Discurso, proposta por Patrick Charaudeau (2008), e em pressupostos no âmbito da Literatura Infantil que abordam o livro ilustrado, postulados por Linden (2009), Nikolajeva e Scott (2011), Paulino (2000) e Ramos (2009).

Palavras-chave: semiolinguística; livro ilustrado; homoparentalidade

\section{Resumen}

La Literatura Infantil contemporánea ha demostrado ser un campo fructífero para abordar temas de fracturados (Ramos, 2009), que reflejan los cambios que se han producido en la sociedad, dando lugar a obras consideradas controvertidas porque sacan a la luz, entre otros temas desafiantes, la homo-afectividad y la homoparentalidad. Se asume que las narrativas constituidas por estos temas fracturados en álbumes de potencial destino infantil pueden adoptar un enfoque pragmático, intermedio entre lo ético y lo estético, narrando para convencer. Se pretende, en este trabajo, analizar las narrativas verbo-visuales: Amor de mãe (Carvalho, 2017) y Meus dois pais (Carrasco, 2010), con el fin de investigar las estrategias discursivas utilizadas para el tratamiento del homo-afecto y de la homoparentalidad en un contrato comunicativo, cuyo potencial destinatario es el niño. El principal aporte teórico para analizar las narrativas seleccionadas en esta investigación se centra en la Teoría Semiolingüística del Análisis del Discurso, propuesta por 
Patrick Charaudeau (2008), y en los supuestos en el ámbito de la Literatura Infantil que abordan el álbum, postulados por Linden (2011), Nikolajeva y Scott (2011), Paulino (2000) y Ramos (2009).

Palabras clave: semiolingüística; álbum ilustrado; homoparentalidad

\begin{abstract}
The contemporary Children's Literature has proved to be a useful field for addressing fracturing themes (Ramos, 2009), that reflect the changes occurred in society, presenting books considered controversial because, among other challenging themes, they deal with homoafectivity and homoparenthood. It is assumed that narratives constituted by these fracturing themes in picturebooks of potential childish destination may take a pragmatic approach, intermediate between the ethical and the aesthetic field, narrating to convince. The aim of this paper is to analyze the verb-visual narratives: Amor de mãe (Carvalho, 2017) and Meus dois pais (Carrasco, 2010), in order to investigate the discursive strategies used for the treatment of homoaffectivity and homoparenthood in a communicative contract, whose potential recipient is the child. The main theoretical support for analyzing the narratives selected focuses on the Semiolinguistic Theory of Discourse Analysis, proposed by Patrick Charaudeau, and on some assumptions within the scope of Children's Literature that investigate the picturebook, postulated by Linden (2011), Nikolajeva and Scott (2011), Paulino (2000) and Ramos (2009).
\end{abstract}

Keywords: semiolinguistics; picturebook; homoparenthood

\title{
PALAVRAS INICIAIS
}

A produção editorial brasileira no âmbito da Literatura Infantil, ainda marcada pela dicotomia divertir e educar, vem abordando assuntos considerados tabus, que, por muito tempo, foram impedidos de ser tratados em livros para a infância. Refletindo a angústia e o sofrimento dos pequenos, inúmeras obras já tematizaram a separação dos pais, a discriminação racial, a desigualdade social, a morte de um ente querido. Além disso, a produção editorial nacional tem dado passos largos também em direção à representação da homossexualidade. Recentemente, ainda que de modo rarefeito, a homoafetividade e a homoparentalidade começaram a figurar em obras destinadas a crianças, especificamente em livros ilustrados.

Nas páginas da vida, no entanto, o Brasil tem escrito outra história. Devido aos elevados índices de violência física, verbal e psicológica contra lésbicas, gays, bissexuais, transsexuais, transgêneros (LGBT), o país tem sido considerado inseguro não só para os que vivem aqui, mas também para os turistas. Embora a mudança da identidade de gênero e da orientação sexual sejam permitidas e garantidas pela lei brasileira, a inclusão de pessoas LGBTs em espaços públicos ainda é um tema controverso, pois a adesão a essa proposta de mundo pode demandar mais tempo para ser aceita por um indivíduo homofóbico do que pelo Estado. De modo geral, no Brasil, dentre os grupos minoritários, os LGBTs parecem ser os mais desvalidos em relação ao reconhecimento de seus direitos civis e de sua própria dignidade humana, já que são mais suscetíveis a sofrer violência verbal e física por assumirem o gênero ou a orientação sexual com a qual se identificam.

É imperioso destacar que a pesquisa acerca da homossexualidade não é de competência exclusiva de analistas homossexuais. Como também não se pode considerar mais legitimada a pesquisa produzida por esse grupo de cientistas. 0 discurso de cerceamento ao homossexual 
atravessa todos os que convivem em sociedades homofóbicas, por isso, o contradiscurso não pode ficar restrito somente a essa minoria. 0 engajamento à luta em defesa das causas LGBTs é o reconhecimento de quem deseja viver em uma sociedade justa para todos. Desse modo, investigar como a homoafetividade e a homoparentalidade têm sido postas em discurso no livro ilustrado potencialmente endereçado a crianças é uma oportunidade impreterível. Além disso, a leitura assídua de livros ilustrados revela como esse é um tipo editorial instigante não só para o leitor destinatário, mas também para o analista, pois, dentre outras características, esse é um tipo de obra que apresenta relações desafiadoras entre palavra e imagem.

Vale também destacar que esta é uma pesquisa que se inscreve no campo de Estudos de Linguagem, sob a perspectiva da Análise do Discurso Semiolinguística, proposta por Charaudeau (2008). Portanto, o principal objetivo deste trabalho concentrou-se em analisar o contrato de comunicação estabelecido em obras de natureza verbo-visual, que se destinam principalmente a crianças e abordam a homoparentalidade e a homoafetividade. Os outros objetivos que o norteiam são: i. identificar os parceiros e os protagonistas no contrato comunicativo que se estabelece entre adultos e crianças em livros ilustrados que abordam essas temáticas fraturantes; ii. reconhecer as propostas básicas de interlocução nas narrativas e as visadas discursivas que se manifestam nesses livros ilustrados; iii. descrever as estratégias discursivas de captação usadas tanto na parte verbal quanto na parte visual do texto.

Para constituir o corpus de análise, decidiu-se selecionar duas obras brasileiras: um livro ilustrado, Amor de Mãe (Carvalho, 2017), e um livro com ilustração, Meus dois pais (Carrasco, 2010). Para investigar essa relação contratual estabelecida entre o adulto e a criança no livro ilustrado que aborda a homoparentalidade e a homoafetividade, como já mencionado, será empregada principalmente a Teoria Semiolinguística de Análise do Discurso, postulada por Patrick Charaudeau (2008). Para descrever a composição do texto verbo-visual de que o livro ilustrado é constituído, serão utilizados alguns dos conceitos presentes nos estudos sobre o livro ilustrado, postulados por Nikolajeva e Scott (2011), Linden (2011) e Ramos (2009, 2018). Para tratar dos aspectos discursivos da obra, serão aplicadas as visadas discursivas (Charaudeau, 2004a), as estratégias discursivas (Charaudeau, 2009) e as propostas de interlocução em narrativas infantis, propostas por Paulino (2000).

\section{A HOMOSSEXUALIDADE E A HOMOPARENTALIDADE NA LITERATURA INFANTIL BRASILEIRA}

De acordo com Coelho (2000), desde o nascimento da Literatura Infantil, há aqueles que acreditam que esse tipo de literatura deva servir a fins eminentemente artísticos, sem compromisso com a realidade e com os valores ético-sociais vigentes. Nesse caso, pressupõe-se que as obras infantis devam estimular a imaginação e a criatividade. Contudo, a autora pontua que há, também, outras pessoas que consideram ser o papel da Literatura Infantil o de ajudar a criança a se integrar à sociedade, reproduzindo e perpetuando suas crenças, o que implicaria em propósitos relacionados à prescrição de um comportamento determinado ou à transmissão de costumes.

Palo e Oliveira (2001) acreditam que a Literatura Infantil foi idealizada para cumprir uma função utilitário-pedagógica. Desse modo, os objetivos da Literatura Infantil poderiam ser: orientar, preparar, formar a criança. Para essas autoras, esse encargo é reforçado pela representação social com a qual a criança é compreendida no ocidente: um ser em formação, sem autonomia, submisso 
ao adulto; reproduzindo, assim, a estrutura social capitalista, em que se verifica a sobreposição do dominador ao dominado.

É notório o crescimento, nas últimas décadas, da produção contemporânea de livros infantis que abordam temáticas relacionadas a questões sociais, econômicas e até políticas. De acordo com Ramos (2013, p. 302), o tratamento dado a esses temas, considerados difíceis, o gênero e a forma que estruturam obras dessa natureza têm qualificado a Literatura Infantil reconhecidamente como "inclusiva e abrangente". No entanto, percebe-se que alguns temas difíceis parecem ter sido mais tolerados do que outros no campo literário infantil.

De acordo com Martha (2010), em suas origens, a literatura para crianças e jovens não privou seus leitores de temas violentos, mesmo porque as raízes do gênero estão profundamente arraigadas em contos populares, narrativas pródigas em violência de toda sorte, como muitos contos de fadas que veiculam relatos macabros, cenas sangrentas, com sacrifícios humanos, inclusive. Tomlinson (citado em Evans, 2015) concorda que a abordagem da violência na infância não é novidade. Na Grécia Antiga, por exemplo, as crianças eram expostas a contos como o de Chronos, e na Idade Média, as crianças ouviam histórias de decapitação, envenenamento, assassinatos etc. Tatar (1987, citado em Evans, 2015) ainda ressalta que, depois de perceber que suas histórias estavam sendo contadas a crianças, até os irmãos Grimms julgaram o sexo como tema inadequado e a violência, não. Portanto, como se pode perceber, lidar com a violência tem sido mais bem aceito do que abordar a sexualidade na Literatura Infantil.

Ramos (2009) afirma que a homossexualidade começou a ser trabalhada em livros infantis, a partir de 1980, nos Estados Unidos e nos países nórdicos europeus, como resultado da abertura dessas sociedades às reivindicações de várias minorias. Desde então, a homossexualidade e a família homoparental começaram a se tornar temas principais e secundários em criações literárias destinadas a crianças e jovens. No Brasil, no entanto, a publicação de obras nacionais que se ocupem dessas temáticas ainda é muito pequena, a maioria dos livros dessa natureza ainda são traduções de obras estrangeiras e muitos ainda têm a possibilidade de ser censurados. Vale relatar, brevemente, os eventos de restrição à leitura de certas obras, sucedidos, recentemente, no Brasil.

Em 2017, algumas prefeituras municipais dos estados do Espírito Santo, do Paraná, do Mato Grosso do Sul e do Recife impediram a leitura do livro Enquanto o sono não vem (Brant, 2003) em escolas públicas, baseando-se em avaliações equivocadas de pais, de professores e até de políticos, que julgaram a abordagem de incesto inadequada às crianças. É importante ressaltar que se tratava de um reconto sobre uma história popular conhecida em várias regiões brasileiras, e que essa foi uma das obras selecionadas para integrar o acervo do Pacto Nacional pela Alfabetização na Idade Certa (PNAIC), programa financiado pelo Ministério da Educação. No ano seguinte, a obra $O$ menino que espiava pra dentro (Machado, 1983), escrita pela renomada Ana Maria Machado, foi alvo de críticas por parte de pais de alunos em uma escola privada em Recife, que alegaram haver apologia ao suicídio na obra. Ainda em 2018, uma das obras que é objeto de estudo desta pesquisa também foi questionada por pais de alunos e por políticos. Trata-se de Meus dois pais (Carrasco, 2010), que teve a sua circulação impedida nas bibliotecas das escolas municipais em Ijuí, uma cidade do estado do Rio Grande do Sul, de acordo com a orientação do secretário municipal de educação. Em setembro de 2019, durante a Bienal do Livro no Rio de Janeiro, houve uma tentativa de censura, imposta pelo prefeito da cidade, à história em quadrinhos (Heinberg, 2016) que trazia um beijo entre dois personagens masculinos.

Apesar da recepção polêmica que o tratamento dado à sexualidade na Literatura Infantojuvenil vem suscitando no público que não é o seu alvo prioritário, a Literatura Infantil, refletindo 
as mudanças que ocorrem na sociedade, não se furta a abordar temas relacionados à homossexualidade, categorizados como fraturantes (Ramos, 2009), trazendo à luz livros ilustrados que apresentam o respeito à homoafetividade e à homoparentalidade, endereçados a pré-leitores. É o que se percebe, por exemplo, em Amor de Mãe (Carvalho, 2017), uma das obras que compõe o corpus deste trabalho.

Vale destacar que o livro ilustrado, como é conhecido o livro-álbum no Brasil, é um tipo editorial sui generis, de acordo com Ramos (2018), em que se percebe uma interação entre texto, imagem e suporte. Os elementos paratextuais como o formato, a dimensão do livro e o título, por exemplo, influenciam a leitura, à medida que suscitam inferências ou descrevem aspectos característicos da narrativa. No entanto, a especificidade do livro ilustrado concentra-se na conjugação das imagens com o texto linguístico e nas relações resultantes dessa interação.

Entretanto, há outros tipos editoriais que usufruem da relação palavra - imagem de modo muito semelhante ao livro ilustrado, e com este compartem diversas características. 0 livro com ilustração é um desses gêneros, e sua distinção nem sempre é tão clara quanto se presume.

De acordo com Linden (2011), o livro com ilustração apresenta um texto predominante espacialmente, acompanhado de ilustrações, porém autônomo do ponto de vista do sentido. 0 leitor penetra na história por meio do texto, o qual sustenta a narrativa. 0 livro ilustrado, por sua vez, ostenta a predominância espacial da imagem, e a narrativa se faz de modo articulado com o texto. Para Feres (2016), o livro ilustrado é um gênero que apresenta semiose verbo-visual e caráter estético, e o livro com ilustração apenas agrega imagens à narrativa verbal, estabelecendo uma relação de (quase) redundância entre os signos verbal e visual. Por outro lado, Hunt (2010) observa que "essa distinção é, em grande parte, organizacional”, e que a crítica e a teoria, até então, apresentam parâmetros muito limitados para assinalar essas diferenças, a definição do livro com ilustração parece não encontrar correspondência total em obras contemporâneas, como, por exemplo, em Meus dois pais (Carrasco, 2010), umas das obras que integram o corpus de análise deste trabalho. 0 investimento no projeto artístico-estético e na exploração de elementos paratextuais para a produção de sentido nessa obra é muito semelhante ao que se costuma atribuir ao livro ilustrado, como pontua Mattos (2017). Desse modo, esses dois tipos editoriais tornaramse muito difíceis de ser distinguidos entre si, já que compartilham não só a mesma origem, mas também inúmeras características formais.

Como se pode inferir, é sobre a interação palavra-imagem que se concentra a maior dificuldade de discernir quais obras são ou não consideradas livros ilustrados. Entretanto, a definição do livro ilustrado contemporâneo já não pode levar mais em conta só as relações que ocorrem entre a parcela verbal e a parte visual do texto, uma vez que se percebe cada vez mais a influência de elementos paratextuais nesse tipo editorial, oferecendo contribuições significativas para a construção do sentido. Por isso, concorda-se com Ramos (2018, p. 5) ao explicitar que:

Habitualmente definido por elementos paratextuais, como podem ser a capa dura, as dimensões e o formato, a qualidade do papel e o tipo de impressão em quadricromia, para além do reduzido número de páginas (32) e da presença de muitas ilustrações, o livro ilustrado contemporâneo aposta cada vez mais no recurso à página dupla como unidade de leitura, na inclusão de um texto de reduzida extensão, apresentado com carateres de grande dimensão (e, às vezes, de tamanho variável, já o que lettering também é alvo de uma atenção cuidada no processo de criação do livro). Mas é, sobretudo, na conjugação das imagens com o texto linguístico e na criação de uma inter-relação - no sentido de interdependência - entre as linguagens presentes que reside a especificidade do livro ilustrado, uma vez que se trata de uma publicação que se distingue justamente pela sinergia ou simbiose entre texto, imagem e suporte (Linden, 2013), com a criação de uma linguagem híbrida. É por isso que a grande maioria das melhores publicações neste segmento resultam da autoria única de um ilustrador (que é responsável 
também pelo texto) ou de uma autoria partilhada entre escritor e ilustrador (com a colaboração cada vez mais assídua do designer gráfico), em resultado de parcerias cúmplices ao longo de todo o processo criativo.

\section{O CONTRATO DE COMUNICAÇÃO ESTABELECIDO NA LITERATURA INFANTIL}

O contrato de comunicação para a Teoria Semiolinguística (Charaudeau, 2008), em geral, envolve quatro sujeitos, nomeadamente, comunicante e enunciador, no polo de produção; destinatário e interpretante, no polo de recepção. A Semiolinguística concebe o sujeito como uma categoria do discurso, que pode ser ocupada por um ou mais indivíduos na situação de comunicação. Por isso, no contrato de comunicação que se realiza no livro infantil, o sujeito comunicante é preenchido por uma gama de profissionais envolvidos na produção da obra, a saber: o escritor, o ilustrador, o designer gráfico, o editor etc. 0 sujeito enunciador atua em um circuito interno e, nesse contrato, cujo modo de organização discursivo predominante é o narrativo, é ocupado pelo narrador, que atua tanto na parte verbal quanto na parte visual do texto. Ainda no circuito interno, mas no polo de recepção, está o sujeito destinatário, compreendido como a imagem que o narrador produz do público leitor. Já na parte externa, está o sujeito interpretante ou, em termos desse contrato, o leitor real.

Em relação à dinâmica do fazer, ou seja, o espaço externo da situação de comunicação, pode-se perceber que uma obra sobre temas fraturantes como a homoafetividade e a homoparentalidade é produzida não só pelo escritor, mas também pelos interesses do editor que publica e comercializa o livro, ou seja, por uma instância de produção, já que a produção literária dessa natureza parece ter de se submeter a critérios não-literários para alcançar as prateleiras de livrarias e bibliotecas.

O escritor, frequentemente tomado como representante da instância de produção, apesar de não saber por quem o livro será lido, pressupõe as características do indivíduo que ocupará a posição de leitor real da obra. Desse modo, o escritor produz uma imagem desse sujeito, a que se denomina leitor destinatário. Assim sendo, para que um indivíduo se torne o leitor real de uma obra, precisa possuir atributos compatíveis com os do destinatário inscrito nela.

Em obras que abordam temas fraturantes, a criança não possui o monopólio nem do papel de leitor destinatário, nem do papel de leitor real na Literatura Infantil, embora ocupe primordialmente essas duas funções. Adultos também podem se tornar leitores reais de obras infantis, pois há uma dupla audiência inscrita nessas obras, como Nikolajeva e Scott (2011, p. 39) afirmam: "muitos livros ilustrados são claramente destinados a crianças pequenas e adultos sofisticados, comunicando-se em diversos níveis com ambos os públicos".

Embora o sujeito destinatário do contrato de comunicação em livros ilustrados infantis seja constituído, prioritariamente, pela criança, a presença do adulto nessa mesma posição pode ser significativa para influenciar a abordagem temática que se faz nessas obras, principalmente, no que tange aos temas fraturantes como a homossexualidade e a homoafetividade, pois, uma vez que um indivíduo adulto tornase o leitor real de uma obra, ele pode incentivar ou impedir que a criança tenha acesso a ela.

Em se tratando de obras que abordam temas desafiadores, Evans (2015) afirma que muitos escritores, ilustradores e pesquisadores já se pronunciaram sobre o controle que os adultos tentam exercer sobre o que as crianças leem. Por isso, percebese que, para lograr êxito em seu projeto de escritura, é nessa função que a instância de produção concentra a sua atenção para produzir uma 
obra que, por um lado, agrade à criança e, por outro, não desagrade ao adulto. Para fins didáticos, elaborou-se um esquema que demonstra como ocorre o contrato de comunicação nessas obras:

Quadro 1:. Dispositivo do contrato de comunicação estabelecido na Literatura Infantil.

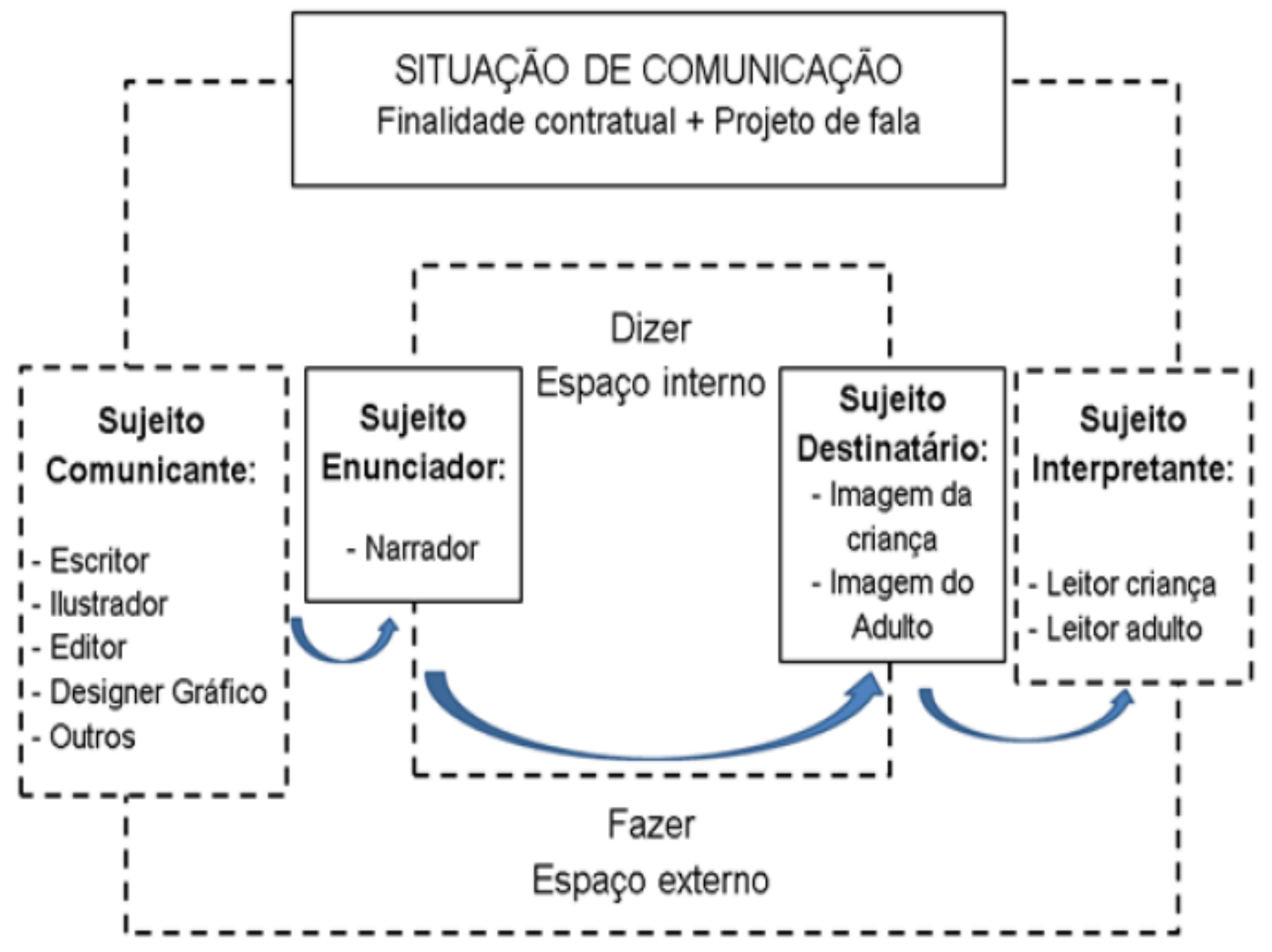

De acordo com Charaudeau (2004a), toda interação comunicativa é motivada por uma intenção psicossociodiscursiva, que corresponde à finalidade do ato de linguagem. Dessa forma, todo ato de linguagem apresenta uma ou mais visadas, que são produzidas a partir da relação de força que o enunciador exerce sobre o destinatário e também da posição que o sujeito enunciador prevê para o destinatário ocupar na troca linguageira. Desse modo, Charaudeau (2004a) descreveu, inicialmente, seis visadas, a saber: informação, incitação, solicitação, prescrição, instrução e demonstração. Em diversos contratos estabelecidos com a criança, verifica-se que as visadas de incitação e de prescrição são, geralmente, as mais selecionadas. Na visada de incitação, o sujeito enunciador deseja mandar-fazer, mas, como não possui autoridade para tal, precisa persuadir ou seduzir o seu destinatário, que, por sua vez, encontra-se em posição de dever acreditar. Na visada de prescrição, o sujeito enunciador, autorizado, quer mandar fazer e, portanto, o sujeito destinatário deve-saber.

A Literatura Infantil sempre esteve atravessada por uma finalidade formativa, por isso, são recorrentes os objetivos ligados à visada de prescrição em histórias infantis. No entanto, em se tratando da abordagem de temáticas fraturantes como a homossexualidade e a homoafetividade, que têm como objetivo fomentar a aceitação e o respeito às diferenças, é preciso convencer 
o leitor destinatário quanto à legitimidade dessas realidades, antes de lhe propor atitudes e comportamentos desejáveis.

Se uma das finalidades de quem escreve (e ilustra) literatura é convencer o sujeito destinatário, seria preciso fazer uso de operações argumentativas para que uma proposição sobre o mundo fosse comprovada e, desse modo, convencer o sujeito interpretante. No entanto, um texto literário não apresenta o discurso sob a dominância do modo argumentativo, pois não é escrito a partir de relações lógicas. Constituído de palavras e imagens, o texto do livro ilustrado é predominantemente narrativo, entretanto, recebe o estatuto de prova em um contrato de comunicação que visa ao convencimento do destinatário. Segundo Charaudeau (2004b), a argumentação é uma atitude impositiva porque obriga o outro a incluir-se em um esquema de verdade. A narração, por sua vez, é uma atitude projetiva por permitir ao outro identificar-se com os personagens de uma trama narrativa.

Ramos (2009) afirma que a abordagem da violência e da agressividade, conotadas como atitudes racistas e xenófobas, é capaz de promover a reflexão e a rejeição a comportamentos preconceituosos e estereotipados. Com o objetivo de identificar o propósito preponderante no texto destinado à criança, Paulino (2000) distinguiu três grandes tendências, pelas quais a instância de produção apresenta a sua proposta de interlocução com o leitor, a saber: i. a proposta de interlocução pragmática, que se refere a um tipo de narrativa, cujo objetivo principal é estimular comportamentos sociais desejáveis, propondo-se a interferir na vida dos destinatários de modo direto; ii. a proposta ficcional, cuja narrativa é detentora de um jogo de significações, que intenta agenciar o imaginário dos leitores e o excita a participar de possibilidades de composição de outros mundos; iii. a proposta informativa, que tem o objetivo de envolver intelectualmente o leitor no acesso e na produção simbólica de conhecimentos, os quais podem ser científicos, sociais e de outras naturezas. Narrar para que o outro fique sabendo é a proposta básica desse tipo de narrativa. Em livros ilustrados predominantemente narrativos, como os que compõem o corpus desta pesquisa, as interlocuções ficcional e pragmática são muito recorrentes.

\section{BREVE ANÁLISE DE FIGURAÇÕES DA HOMOSSEXUALIDADE E DA HOMOPARENTALIDADE NA LITERATURA INFANTIL BRASILEIRA}

Meus dois pais (Carrasco, 2010) é um livro com ilustração, composto integralmente por páginas duplas, em que as imagens sangram as suas margens (Linden, 2011) e a parte verbal da história ocupa sempre um espaço dessemantizado da página. É possível classificar a proposta interlocutória predominante nessa obra como pragmática, uma vez que, em nota, ao fim do livro, o escritor sugere uma mudança de comportamento ao leitor, ao afirmar que é preciso conversar sobre a homossexualidade para entender que alguém pode ser diferente sem ser errado. Para alcançar esse fim, Carrasco (2010) seleciona, pelo menos, duas visadas, uma de incitação e outra de prescrição. 0 escritor visa incitar o leitor a aceitar a homossexualidade, por meio de uma estratégia de captação altamente patêmica para aqueles classificados como leitores em processo (Coelho, 2000).

0 escritor seleciona, como intriga para sua narrativa, um momento conflituoso na vida de uma criança, a descoberta da homossexualidade de seu pai, apresentando uma narrativa linear, composta por início, meio e fim. A proposta pragmática de Carrasco (2010) também está ligada a uma visada de prescrição, pois recomenda o comportamento ético de aceite e de respeito à 
homossexualidade dentro do próprio texto, na fala de uma das personagens, neste caso a mãe do menino Naldo, e no peritexto já mencionado, dirigido ao leitor ao fim do livro.

Naldo é o protagonista dessa história e um narrador-contador que conta a sua própria história (Charaudeau, 2008). 0 garoto inicia seu relato, afirmando que, apesar de ter ficado triste com a separação de seus pais, sentia-se aliviado por não ter mais de vê-los brigando. 0 menino declara ainda que gostava muito de passar os fins de semana com o pai, principalmente, depois da chegada de Celso, um amigo que passou a morar com ele. Entretanto, Naldo vai morar com os dois, por causa de uma mudança no emprego da mãe, e fica confuso com o fato de Celso dormir no mesmo quarto que seu pai. Contudo, infere-se que esse costume incomum na amizade entre dois homens parece ter deixado de ser uma ideia estranha ao menino e não influenciava na convivência entre os três, pois não há nenhuma menção a conflitos decorrentes dessa situação.

Antes que Celso e o pai de Naldo fossem identificados pelo menino como homossexuais, a relação familiar entre os três era agradável: "Eu sentia falta da mamãe, é claro. Mas a vida estava muito boa com os dois cuidando de mim" (Carrasco, 2010, p. 19) e até superava a de outras famílias: "Alguns dos meus colegas ficavam chateados porque os pais não estavam nem aí para as reuniões. Mas o papai e o Celso queriam saber de tudo o que acontecia comigo na escola, então foram à reunião" (Carrasco, 2010, p. 20).

Quando Naldo ouve de seus amigos que seu pai é gay, o garoto desloca a representação positiva que tinha feito a respeito da relação entre Celso e o pai para uma pejorativa, rejeitada socialmente. No momento em que o pai de Naldo e o Celso são categorizados como homossexuais, o menino ainda questiona a incompatibilidade entre as características pessoais do pai e de Celso com um imaginário sociodiscursivo que concebe o homossexual como alguém incomum, um homem que mantém características femininas:

O papai tinha sido casado. Como podia ser gay?

Mas por que justo meu pai tem que ser diferente?

Mas o meu pai não é delicado, nem o Celso! (Carrasco, 2010, pp. 22-30)

Mesmo constatando incongruências, o menino sucumbe aos estereótipos e se recusa a continuar vivendo bem com o casal, passando a morar com a avó, onde não lhe é prestada a mesma atenção. Com isso, verifica-se o que Foucault (1988) afirma sobre as sexualidades periféricas, quando, no século XIX, houve incorporação das perversões e nova especificação dos indivíduos, transformando o homossexual, que outrora era visto como um sodomita reincidente, em um personagem.

Nada daquilo que ele é, no fim das contas, escapa à sua sexualidade. Ela está presente nele todo: subjacente a todas as suas condutas, já que ela é o princípio insidioso e infinitamente ativo das mesmas; inscrita sem pudor na sua face e no seu corpo já que é um segredo que se trai sempre. É-lhe consubstancial, não tanto como pecado habitual, porém como natureza singular. (Foucault, 198, p. 43)

Essa ideia está implicitamente metaforizada na explicação que a mãe de Naldo usa para responder o questionamento do filho:

- Mas por que justo meu pai tem que ser diferente?

Na mesa ainda havia uma bandeja de doces. A mamãe

pegou um de chocolate e outro de amêndoas.

- Olhe esses doces. Ambos são doces, mas diferentes entre

si. Não é errado ser diferente! Imagine se todo mundo

tivesse cabelo igual, nariz igual, rosto igual? Jeito de ser

igual? (Carrasco, 2010, p. 30) 
0 que a mãe de Naldo quer mostrar ao menino é que as pessoas podem distinguir-se umas das outras por características físicas e psicológicas. No entanto, ao afirmar que não é errado ser diferente, infere-se que a mãe do menino esteja se referindo à orientação sexual do ex-marido, a qual é dissonante de um padrão convencionado. Ao distinguir um indivíduo pela sua orientação sexual, atribui-se à homossexualidade a causa de todas as características do sujeito. Por outro lado, não se costuma relacionar as qualidades do sujeito heterossexual à sua orientação sexual.

Em Amor de mãe (Carvalho, 2017), o protagonista Luan é um menino negro que parece ter sido posto para adoção ainda bebê e, logo, foi adotado por um casal de mulheres. A narrativa sucede na escola quando Luan está a escrever cartões para o dia das mães. Entretanto, o narrador afirma que essa é uma atividade mais trabalhosa para o menino, já que ele deve confeccionar não apenas um, mas dois cartões para homenagear suas mães. A partir disso, o narrador apresenta a rotina de Luan com cada uma delas, mostrando o quanto essas mulheres são diferentes entre si e como o menino se sente feliz ao lado das duas. 0 narrador ainda destaca o fato de Luan ter conhecimento de sua origem, inclusive que seu nome lhe fora dado por sua mãe biológica. A história termina com a afirmação do amor de Luan por suas duas mães adotivas.

Amor de mãe (Carvalho, 2017) é um livro ilustrado que apresenta sua diagramação por associação (Linden, 2011), em que a parte verbal ocupa a mesma página que a parcela visual, embora situada sempre em um espaço dessemantizado da cena. Tal como a outra obra analisada, Amor de mãe (Carvalho, 2017) é composta integralmente por páginas duplas, cuja parcela visual sangra às margens da página. Assim como a maioria dos livros ilustrados que se apresentam dessa forma, em Amor de Mãe (Carvalho, 2017), não há marcação numérica de páginas.

Nessa narrativa destinada a leitores iniciantes (Coelho, 2000), percebe-se que há fatos da vida do menino e de suas mães que não se ligam diretamente à situaçãoproblema apresentada, a escrita de dois cartões para o dia das mães. Conforme Charaudeau (2008) postula, o encadeamento desses fatos durante o percurso narrativo realiza-se a partir de encaixes, em que micro-sequências são incluídas no interior de uma sequência mais ampla para detalhar certos aspectos da narrativa ou dos personagens. Ao nível semântico, percebe-se que as micro-sequências evocadas estão a serviço da qualificação das mães de Luan, caracterizando-as e as distinguindo entre si. Essas micro-sequências inseridas na narrativa atuam como uma grande digressão para mostrar como é a convivência do menino com cada uma de suas mães.

Em Amor de mãe (Carvalho, 2017), percebe-se que as visadas discursivas de incitação e de demonstração (Charaudeau, 2004a) permeiam propostas interlocutórias pragmática e ficcional (Paulino, 2000). A instância de produção interpela o leitor destinatário por meio de uma proposta ficcional, altamente verossímil, que, diferentemente da obra anterior, possibilita a verificação de sua proposição de mundo fora da ficção. A obra apresenta uma situação recorrente na escola, sobretudo para alunos do primeiro segmento do Ensino Fundamental: a escrita de um cartão para as mães, em razão da data em que convencionalmente comemora-se o seu dia. A ambientação do enredo em um local familiar para a criança, portanto, acessível à experiência do leitor destinatário, é um elemento que contribui para a identificação do leitor real com a obra.

A visada de demonstração tem o objetivo de comprovar a proposição de mundo feita pela instância de produção, a saber: uma criança pode crescer feliz e amada, sendo criada por um casal homossexual. Ligada à proposta ficcional (Paulino, 2000), a visada de demonstração (Charaudeau, 2004a) é responsável pela figuração do enredo, que neste caso, contou com a verossimilhança como estratégia de captação. Uma vez seduzido, o leitor é capaz de projetar-se na narrativa e aderir à proposta de mundo que lhe é apresentada, o que concretiza a visada de incitação (Charaudeau, 
2004a) na proposta pragmática da obra (Paulino, 2000). Em Amor de mãe (Carvalho, 2017), a proposta pragmática prevê que o leitor creia na licitude da homoafetividade e, consequentemente, da homoparentalidade.

\section{CONSIDERAÇÕES FINAIS}

O contrato de comunicação que se realiza por meio do livro ilustrado, destinado potencialmente à criança, apresenta especificidades que refletem a natureza e o surgimento da Literatura Infantil, como, por exemplo, a presença majoritária do adulto na posição de sujeito enunciador, o ser detentor de saberes, conhecimentos e experiências, autorizado a tutelar a criança.

No entanto, os livros ilustrados são capazes de representar mundos ficcionais altamente verossímeis, baseados em imaginários sociodiscursivos; e o jogo de significações proporcionado pela engrenagem verbo-visual que os constitui agrega ainda mais efeitos patêmicos para a sensibilização e a projeção do leitor à narrativa. Desse modo, partindo do pressuposto de que a Literatura Infantil não só diverte e ensina, mas também seduz o leitor ao lançar uma proposta sobre o mundo, acredita-se que os livros ilustrados que abordam temas fraturantes como a homoafetividade e a homoparentalidade narram para fazer crer.

No caso das temáticas em questão, estima-se que a visada discursiva principal nessas obras seja incitar o leitor a crer na licitude do relacionamento homoafetivo e na legitimidade da família homoparental. Por isso, o enredo dessas narrativas não abarca a homofobia, nem representa o sofrimento de casais homossexuais que são vítimas de injúrias. Por outro lado, percebe-se que esses não são livros produzidos exclusivamente para cumprir uma demanda por comportamentos sociais éticos. Essas obras apresentam enredos para educar; no entanto, percebe-se que a cobertura figurativa delas é potencialmente patêmica, e os jogos de sentido, que a integração entre a parcela visual e a parte verbal instauram, proporcionam ao leitor uma experiência estética e um aprimoramento de suas habilidades cognitivas.

As obras selecionadas para esta análise demonstram como uma intencionalidade argumentativa pode estar implícita em uma narrativa endereçada a crianças. À Literatura Infantil sempre foi solicitado o cumprimento de um propósito formativo, que disseminasse os valores éticos requeridos à convivência social harmônica. Apesar de essa concepção já ser aceita entre os estudiosos, percebe-se que, por meio da Literatura Infantil, para além dos objetivos educativos, pode-se promover um processo de espelhamento social entre a criança e as representações que lhe são expostas nos livros, capaz de fazê-la refletir sobre a situação-problema abordada na obra.

Nas obras que compõem o corpus de análise deste trabalho, percebe-se as propostas pragmática e ficcional. Na obra de Carrasco (2010), verifica-se que a proposta pragmática é a dominante e que está estritamente ligada a uma visada de prescrição, pois recomenda o comportamento ético de aceite e de respeito à homossexualidade. Na obra de Carvalho (2017), por sua vez, a proposta pragmática também é a dominante, mas está relacionada, diretamente, a uma visada de demonstração, pois se pode perceber maior ênfase em comprovar que a homoafetividade e a homoparentalidade são formas legítimas de amar e de formar famílias.

A proposta de ficção também está presente nas duas obras e pode ser verificada não só por meio da própria finalidade do contrato, que, usando narrativas verossímeis, se propõe a pôr em discurso os problemas relacionados a não-aceitação da homossexualidade e da homoparentalidade, mas 
também pelo modo como a história é contada pelo narrador, a partir da sua própria fantasia e de seu saber artístico.

As duas obras analisadas, intencionalmente, são ambientadas em recintos domésticos, recriando um universo fictício altamente verossímil e patêmico o suficiente para comover o leitor criança e fazê-lo confrontar os imaginários sociodiscursivos estereotipados e depreciativos, consolidados na sociedade contemporânea, com as figurações que lhe são propostas nessas obras. Verifica-se, portanto, que essas obras podem ser altamente eficientes para que uma finalidade argumentativa, cuja principal visada seja incitar o leitor destinatário a crer na licitude da relação homoafetiva e na legitimidade da homoparentalidade, seja bem sucedida.

No entanto, como se pode presumir, livros como esses ainda não são selecionados para compor as listas de leituras escolares, seja por serem julgados inadequados para as crianças, seja por serem considerados desafiadores para os mediadores. Consequentemente, limita-se a possibilidade de expressão e de conscientização, intrínseca à literatura, propícia para a humanização dos indivíduos.

\section{Referências bibliográficas}

Brant, J. M. (2003). Enquanto o sono não vem. Rocco.

Carrasco, W. (2010). Meus dois pais [Ilust. Laurent Cardon]. Ática.

Carvalho, L. (2017). Amor de mãe [Ilust. Aline Casassa]. Bamboozinho.

Charaudeau, Patrick (2004a). Visadas discursivas, gêneros situacionais e construção textual. Em I. L. Machado (Ed.), Gêneros: reflexões em Análise do Discurso (pp. 13-42). FALE/UFMG.

Charaudeau, Patrick (2004b). A argumentação talvez não seja o que parece ser. Em M. E. Giering e M. Teixeria (Eds.), Investigando a linguagem em uso: estudos em Linguística Aplicada (pp. 33-44). Editora Unisinos.

Charaudeau, Patrick (2008). Linguagem e discurso: Modos de organização [Trad. Angela M. S. Corrêa e Ida Lúcia Machado]. Contexto.

Charaudeau, Patrick. (2009). Identidade social e identidade discursiva, o fundamento da competência comunicacional. Em M. Pietroluongo (Ed.). O trabalho da tradução (pp. 309-326). Contra Capa.

Coelho, N. (2000). Literatura Infantil: teoria, análise, didática. Moderna.

Evans, J. (2015). Challenging and controversial picturebooks: creative and critical responses to visual texts. Routledge.

Feres, B. (2016). A função descritivo-discursiva da verbovisualidade em livros ilustrados. Elos. Revista de Literatura Infantil e Xuvenil, 3, 5-31. https://doi.org/10.15304/elos.3.2809

Foucault, M. (1988). A história da sexualidade I - A vontade de saber [Trad. Maria Thereza da Costa Albuquerque e J. A. Guilhon Albuquerque]. Edições Graal.

Heinberg, A. (2016). Os vingadores - A cruzada das crianças [Ilust. Jim Cheung]. Salvat.

Hunt, P. (2010). Crítica, Teoria e Literatura Infantil [Trad. Cid Knipel]. Cosac Naify

Linden, S. V. (2011). Para ler o livro ilustrado [Trad. Dorothée de Bruchard]. Cosac Naify.

Machado, A. M. (1983). O menino que espiava pra dentro [Ilust. Flavia Saravy]. Nova Fronteira.

Martha, A. A. P. (2010). Narrativas de língua portuguesa: temas de fronteira para crianças e jovens. Em M. J. Marçalo, M. C. Lima-Hernandes, E. Esteves, Mํㅡㄹ do C. Fonseca, O. Gonçalves, A. L. Vilela e A. A. Silva (Eds.), II Simpósio Mundial de Estudos de Língua Portuguesa (p. 1-22). Universidade de Évora. https://arqui vo.pt/wayback/20170222142729mp_/http://www.simelp2009.uevora.pt/pdf/slt59/02.pdf 
Mattos, M. S. (2017). Editores consagrados, ilustradores renomados, palavra e imagem entrelaçadas Ingredientes de contratos de comunicação literários renovados [tese de doutoramento]. Universidade Federal Fluminense.

Nikolajeva, M. e Scott, C. (2011). Livro ilustrado: palavras e imagens [Trad. Cid Knipel]. Cosac Naify.

Palo, M. J. e Oliveira, M. R. (2001). Literatura Infantil - voz de criança. Ática.

Paulino, G. (2000). Diversidade das narrativas. Em A. Paiva, A. Evangelista, G. Paulino e Z. Versiani (Orgs.), No fim do século: a diversidade - o jogo infantil e juvenil (pp. 39-48). Autêntica.

Ramos, A. M. (2009). Saindo do Armário - Literatura para a infância e a reescrita da homossexualidade. Forma Breve, 7, 295-314. https://doi.org/10.34624/fb.v0i7.6649

Ramos, A. M. (2013). As famílias não tradicionais na literatura para a infância e a juventude: a representação da homoparentalidade. Em A. M. Ramos e C. Ferreira Boo (Eds.), A família na literatura infantil e juvenil (pp. 301-317). ANILIJ/CIEC-Universidade do Minho.

Ramos, A. M. (2018). Desafios da leitura do livro ilustrado pós-moderno: formar melhores leitores cada vez mais cedo. Sede de Ler, 5, 5-8. https://periodicos.uff.br/sededeler/article/view/29126

Cita: Azerêdo de Paula, Anabel Medeiros (2021). "Narrar para fazer crer: a homoparentalidade em livros ilustrados infantis". Elos. Revista de Literatura Infantil e Xuvenil, 8, “Artigos”, 1-13. ISSN 2386-7620. DOI http://dx.doi.org/10.15304/elos.8.7097 